\title{
ASSOCIATION OF INCREASING PARITY WITH UTERINE CURETTAGE IN PLACENTA PREVIA PATIENTS.
}

\author{
DR. ANDLEEB TABASSUM \\ NISHTAR HOSPITAL, MULTAN, PAKISTAN. \\ DR. MASABA ANDLEEB, MBBS \\ NISHTAR HOSPITAL, MULTAN, PAKISTAN.
}

DR. MUHAMMAD ZOHAIB SADIQ, MBBS

NISHTAR HOSPITAL, MULTAN, PAKISTAN.

\begin{abstract}
Background; Placenta Previa is an obstetric complication that occurs in the second and third trimester of pregnancy. It may cause serious morbidity and mortality to the mother. This study was conducted to ascertain uterine curettage in placenta previa. Objective; To determine association of increasing parity with uterine curettage in patients with placenta previa at a tertiary care hospital. Subjects and Methods; A total 96 patients with placenta previa aged $20-45$ years having placenta previa were enrolled from Department of Obstetrics \& Gynaecology, Nishtar Hospital, Multan in this cross-sectional study. Data was entered and analyzed by SPSS version 20.0. Results; Our study comprised of a total of 96 patients meeting inclusion criteria of our study. Mean gestational age of our study cases was $38.56 \pm 1.25$ weeks. Mean age of our study cases was $31.20 \pm 4.91$ years (with minimum age of our study cases was 24 years while maximum age was 42 years). Our study results have indicated that majority of our study cases i.e. $62(64.6 \%)$ were aged more than 30 years. Of these 96 study cases, $52(54.2 \%)$ belonged to rural areas and $44(45.8 \%)$ belonged to urban areas. Of these 96 study cases $58(60.4 \%)$ were having poor socioeconomic status and $38(39.6 \%)$ belonged to middle income families. Of these 96 study cases, $51(53.1 \%)$ were illiterate while $45(46.9 \%)$ were literate. Previous history of cesarean section was positive in $55(57.3 \%)$ of our study cases. Mean body mass index of our study cases was $27.64 \pm 2.11 \mathrm{~kg} / \mathrm{m}^{2}$ and obesity was present in $30(31.3 \%)$ of our study cases. Mean parity of our study cases was $4.18 \pm 1.24$ and $51(53.1 \%)$ had parity more than 3 . Placenta previa type 1 was present in 4 (4.2\%), type 2 in $29(30.2 \%)$, type 3 placenta previa in $26(27.1 \%)$ and $37(38.5 \%)$ had type 4 placenta previa. Uterine curettage was noted in $49(51 \%)$ and significant association with increasing parity was noted. Conclusion; Very high frequency of uterine curettage was noted among patients presenting with placenta previa in our study. Uterine curettage was significantly associated with obesity, increasing parity and type of placenta previa.
\end{abstract}

Keywords; Placenta previa, uterine curettage, Frequency.

DOI: $10.7176 / \mathrm{JMPB} / 68-05$

Publication date:December $30^{\text {th }} 2020$

\section{INTRODUCTION:}

Placenta previa complicates approximately $0.3-0.5 \%$ of pregnancies with no prior cesarean delivery ${ }^{1}$. In placenta previa (PP), the placenta is located over or very near the internal cervical os ${ }^{2,3}$. Maternal and fetal morbidity and mortality from PP are considerable, and associated with high demands on health care resources. Given the rising incidence of cesarean section combined with increasing maternal age, the number of cases of PP and its complications, including placenta accreta (PA), will continue to increase ${ }^{4}$.

The risk of developing placenta previa increase progressively with increasing in number of cesarean sections with $\geq 3$ cesarean deliveries the chance of having previa is $37 \%$. Other risks for placenta previa include uterine surgery, increasing maternal age, high parity, multi-fetal gestation, smoking and cocaine use ${ }^{5}$. Uterine curettage has been 
reported to be $46 \%$ in patients with placenta previa ${ }^{6}$. Studies have shown that placenta previa carries greater risks of surgical complications including obstetrics hysterectomy and massive haemorrhage requiring blood transfusion 7.

Surgical injury to the bladder, viscera, and ureters and renal failure may occur. Massive obstetrical haemorrhage in placenta previa is associated with severe maternal morbidity and mortality worldwide accounting for $30 \%$ maternal deaths in Asia. There are several neonatal complications associated with placenta previa that are often related to prematurity ${ }^{8}$. PP is known to be associated with prematurity. However, there is debate about the effect of PP on fetal growth; some studies have suggested that pregnancies with PP are at risk of low birth weight and a low Apgar score ${ }^{9}$. The purpose of this study is to document current magnitude of the problem among targeted population.

\section{MATERIALS AND METHODS:}

A total 96 patients with placenta previa aged 20 - 45 years having placenta previa were enrolled from Department of Obstetrics \& Gynaecology, Nishtar Hospital, Multan in this cross-sectional study. Informed written consent was taken from each patient before inclusion. Detailed history and physical examination of our study cases was arranged by the researcher itself. These study cases/patients underwent baseline investigations like ultrasonography (done by a consultant Sonologist having more than 5 years) to diagnose different stages of placenta previa and previous history of uterine curettage. All the data was entered and analyzed by using SPSS version 20.0. The quantitative variables like age, BMI and gestational age were presented as mean and standard deviation. Frequencies and percentages were calculated for age groups, type of placenta previa, uterine curettage, residential status, previous history of cesarean sections and educational status. Effect modifiers like age, parity, obesity, residential status, type of placenta previa, previous history of cesarean sections and obesity were controlled through stratification and post-stratification student chi-square test was applied to see their effect on outcome. Pvalue $\leq 0.05$ was considered as significant.

\section{RESULTS;}

Our study comprised of a total of 96 patients meeting inclusion criteria of our study. Mean gestational age of our study cases was $38.56 \pm 1.25$ weeks. Mean age of our study cases was $31.20 \pm 4.91$ years (with minimum age of our study cases was 24 years while maximum age was 42 years). Our study results have indicated that majority of our study cases i.e. $62(64.6 \%)$ were aged more than 30 years. Of these 96 study cases, $52(54.2 \%)$ belonged to rural areas and $44(45.8 \%)$ belonged to urban areas. Of these 96 study cases $58(60.4 \%)$ were having poor socioeconomic status and $38(39.6 \%)$ belonged to middle income families. Of these 96 study cases, $51(53.1 \%)$ were illiterate while $45(46.9 \%)$ were literate. Previous history of cesarean section was positive in $55(57.3 \%)$ of our study cases. Mean body mass index of our study cases was $27.64 \pm 2.11 \mathrm{~kg} / \mathrm{m}^{2}$ and obesity was present in 30 $(31.3 \%)$ of our study cases. Mean parity of our study cases was $4.18 \pm 1.24$ and $51(53.1 \%)$ had parity more than 3. Placenta previa type 1 was present in $4(4.2 \%)$, type 2 in $29(30.2 \%)$, type 3 placenta previa in $26(27.1 \%)$ and $37(38.5 \%)$ had type 4 placenta previa. Uterine curettage was noted in $49(51 \%)$ and significant association with increasing parity was noted (Table No. 1). 
Table No. 1

\section{Stratification of Uterine curettage with regards to Parity.}

$$
(\mathrm{n}=96)
$$

\begin{tabular}{|c|c|c|c|c|c|}
\hline \multirow{2}{*}{ Parity } & \multicolumn{4}{|c|}{ Uterine curettage } & \multirow{2}{*}{$P$ - value } \\
\hline & Yes & $(n=49)$ & No & $(n=47)$ & \\
\hline $\begin{array}{l}\text { Up to } 3 \\
(n=45)\end{array}$ & & 4 & & 31 & \multirow{3}{*}{0.001} \\
\hline $\begin{array}{c}\text { More than } 3 \\
(n=51)\end{array}$ & & 5 & & 6 & \\
\hline Total & \multicolumn{4}{|c|}{96} & \\
\hline
\end{tabular}

\section{DISCUSSION;}

Placenta previa is an obstetric complication characterized by placental implantation into the lower segment of the uterine wall, covering whole (major) or part (minor) of the cervix ${ }^{10-12}$. It complicates $0.4 \%$ of pregnancies at term ${ }^{13}$, 14. Placenta previa usually presents with painless vaginal bleeding in the late second or early third trimester. It is diagnosed on ultrasound during the second trimester or incidentally during an operation ${ }^{15-18}$.

Our study comprised of a total of 96 patients meeting inclusion criteria of our study. Mean gestational age of our study cases was $38.56 \pm 1.25$ weeks. Shaikh et al ${ }^{19}$ also reported $38 \pm 1.4$ years mean gestational age of the patients with placenta previa which is close to our study results.

Mean age of our study cases was $31.20 \pm 4.91$ years (with minimum age of our study cases was 24 years while maximum age was 42 years). Our study results have indicated that majority of our study cases i.e. 62 (64.6\%) were aged more than 30 years. Shaikh et al ${ }^{19}$ also reported $30.1 \pm 5.6$ years mean age of the patients with placenta previa which is close to our study results. A study conducted by Omokonye et al ${ }^{18}$ also reported similar results. A study conducted by Senkoro et al ${ }^{20}$ has also reported $29.07 \pm 6.12$ years mean age of the patients with placenta previa which is close to our study results. Nasreen et al ${ }^{6}$ has reported similar results. A study conducted by Raheel et al ${ }^{21}$ also reported $31.09 \pm 5.38$ years mean age of the patients with placenta previa which is close to our study results.

Of these 96 study cases, $52(54.2 \%)$ belonged to rural areas and 44 (45.8\%) belonged to urban areas. Of these 96 study cases $58(60.4 \%)$ were having poor socioeconomic status and $38(39.6 \%)$ belonged to middle income families. A study conducted by Omokonye et al ${ }^{18}$ also reported $81.4 \%$ women with placenta previa were from poor families which is in accordance with our study findings. A study conducted by Senkoro et al ${ }^{20}$ has also reported $71.1 \%$ patients with placenta previa belonged to rural areas which is in compliance with our study results.

Of these 96 study cases, 51 (53.1\%) were illiterate while 45 (46.9\%) were literate. Previous history of cesarean section was positive in $55(57.3 \%)$ of our study cases. Omokonye et al ${ }^{18}$ also reported $47.4 \%$ women with placenta previa had previous history of cesarean section deliveries which is close to our study results.

Mean body mass index of our study cases was $27.64 \pm 2.11 \mathrm{~kg} / \mathrm{m}^{2}$ and obesity was present in $30(31.3 \%)$ of our study cases. Shaikh et al ${ }^{19}$ also reported $28.4 \pm 5.9 \mathrm{~kg} / \mathrm{m}^{2}$ which is in compliance with our study results.

Mean parity of our study cases was $4.18 \pm 1.24$ and $51(53.1 \%)$ had parity more than 3 . Shaikh et al ${ }^{19}$ also reported $4.02 \pm 1.2$ which is close to our study results. A study conducted by Omokonye et al ${ }^{18}$ also reported $35.4 \%$ parity $2-4$ and $51.2 \%$ had parity more than 5 which is in compliance with our study results. In a study conducted by Nasreen et al ${ }^{6}, 43 \%$ had parity $1-4$ while $45 \%$ had parity equal or more than 5 which is close to our study results.

Placenta previa type 1 was present in 4 (4.2\%), type 2 in $29(30.2 \%)$, type 3 placenta previa in $26(27.1 \%)$ and 37 $(38.5 \%)$ had type 4 placenta previa. Shaikh et al ${ }^{19}$ also reported similar results. In a study conducted by Nasreen et al ${ }^{6}$, type 1 placenta previa was noted in $7 \%$, type 2 placenta previa in $29 \%$, type 3 placenta previa in $27 \%$ and type 4 placenta previa was noted in $37 \%$ which is in compliance with our study results. 
Uterine curettage was noted in $49(51 \%)$ of our study cases. In a study conducted by Nasreen et al, uterine curettage has been reported to be $46 \%$ in patients with placenta previa ${ }^{6}$ which in accordance with our study results.

\section{CONCLUSION;}

Very high frequency of uterine curettage was noted among patients presenting with placenta previa in our study. Uterine curettage was significantly associated with obesity, increasing parity and type of placenta previa.

\section{REFERENCES:}

1. Kancherla $\mathrm{V}^{1}$, Räisänen $\mathrm{S}^{1,2}$, Gissler $\mathrm{M}^{3,4}$, Kramer $\mathrm{MR}^{1}$, Heinonen $\mathrm{S}^{2,5}$. Placenta previa and risk of major congenital malformations among singleton births in Finland. Birth Defects Res A Clin Mol Teratol. 2015;103(6):527-35.

2. Silver $\mathrm{RM}^{1}$. Abnormal Placentation: Placenta Previa, Vasa Previa, and Placenta Accreta. Obstet Gynecol. 2015;126(3):654-68.

3. Abduljabbar HS ${ }^{1}$, Bahkali NM, Al-Basri SF, Al Hachim E, Shoudary IH, Dause WR, et al. Placenta previa. A 13 years experience at a tertiary care center in Western Saudi Arabia. Saudi Med J. 2016;37(7):762-6.

4. Kassem $\mathrm{GA}^{1}$, Alzahrani $\mathrm{AK}^{2}$. Maternal and neonatal outcomes of placenta previa and placenta accreta: three years of experience with a two-consultant approach. Int J Womens Health. 2013;5:803-10.

5. Lyu $\mathrm{B}^{1}$, Chen $\mathrm{M}$, Liu XX. Risk factors of peripartum hysterectomy in placenta previa: a retrospective study of 3840 cases. Zhonghua Fu Chan Ke Za Zhi. 2016;51(7):498-502.

6. Nasreen F. Incidence, causes and outcome of placenta previa. J Postgrad Med Inst. 2011;17(1);99-104.

7. Fan $\mathrm{D}^{1}$, Wu S, Wang W, Xin L, Tian G, Liu L, et al. Prevalence of placenta previa among deliveries in Mainland China: A PRISMA-compliant systematic review and meta-analysis. Medicine (Baltimore). 2016 Oct;95(40):e5107.

8. Downes $\mathrm{KL}^{1}$, Hinkle $\mathrm{SN}^{2}$, Sjaarda $\mathrm{LA}^{2}$, Albert $\mathrm{PS}^{3}$, Grantz $\mathrm{KL}^{4}$. Previous prelabor or intrapartum cesarean delivery and risk of placenta previa. Am J Obstet Gynecol. 2015 May;212(5):669.e1-6.

9. Nørgaard LN, Pinborg A, Lidegaard Ø, Bergholt T. A Danish national cohort study on neonatal outcome in singleton pregnancies with placenta previa. Acta Obstet Gynecol Scand. 2012;91:546-551.

10. Faiz AS, Ananth CV. Etiology and risk factors for placenta previa: an overview and meta-analysis of observational studies. J Matern Fetal Neonatal Med 2003; 13:175.

11. Nørgaard LN, Pinborg A, Lidegaard Ø, Bergholt T. A Danish national cohort study on neonatal outcome in singleton pregnancies with placenta previa. Acta Obstet Gynecol Scand. 2012;91:546-51.

12. Simon EG, Fouche CJ, Perrotin F. Three-dimensional transvaginal sonography in third-trimester evaluation of placenta previa. Ultrasound Obstet Gynecol. 2013;41:465-8.

13. Spong CY, Mercer BM, D'alton M, Kilpatrick S, Blackwell S, Saade G. Timing of indicated latepreterm and early-term birth. Obstet Gynecol. 2011;118:323-33.

14. Goodnough LT, Daniels K, Wong AE, Viele M, Fontaine MF, Butwick AJ. How we treat: transfusion medicine support of obstetric services. Transfusion. 2011;51:2540-8.

15. Ravelli AC, Jager KJ, de Groot MH, Erwich JJ, Rijninks-van Driel GC, Tromp M, et al. Travel time from home to hospital and adverse perinatal outcomes in women at term in the Netherlands. BJOG. 2011;118:457-65.

16. Vahanian $\mathrm{SA}^{1}$, Lavery $\mathrm{JA}^{2}$, Ananth $\mathrm{CV}^{3}$, Vintzileos $\mathrm{A}^{4}$. Placental implantation abnormalities and risk of preterm delivery: a systematic review and metaanalysis. Am J Obstet Gynecol. 2015 Oct;213(4 Suppl):S78-90.

17. Silver $\mathrm{RM}^{1}$. Abnormal Placentation: Placenta Previa, Vasa Previa, and Placenta Accreta. Obstet Gynecol. 2015 Sep;126(3):654-68.

18. Omokanye $\mathrm{LO}^{1}$, Olatinwo $\mathrm{AWO}^{1}$, Salaudeen $\mathrm{AG}^{2}$, Ajiboye $\mathrm{AD}^{1}$, Durowade $\mathrm{KA}^{3}$. A 5-year review of pattern of placenta previa in Ilorin, Nigeria. Int J Health Sci (Qassim). 2017 Apr-Jun;11(2):35-40.

19. Shaikh S. Frequency of placenta previa in multgravida at a tertiary care hospital. Int J Curr Res Rev. 2014;6(23):39-43

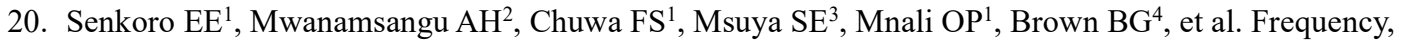
Risk Factors, and Adverse Fetomaternal Outcomes of Placenta Previa in Northern Tanzania. J Pregnancy. 2017;2017:5936309.

21. Raheel R, Tabassum R, Bhutto A, Riaz H, Hanif R. Fetal outcome in cases of placenta previa - a retrospective study. Med Channel Apr - Jun 2010;16(2):256-9. 